\title{
Los Pasos Perdidos. el Azar y la Aventura
}

El vago azar o las precisas leyes Borges

De entre los diferentes elementos que unifican y dan continuidad a la narrativa de Carpentier, la búsqueda de los orígenes es sin duda el más sobresaliente. El destino de sus personajes se va definiendo por medio de una indagación de la realidad circundante, o a través de un desplazamiento por espacios y latitudes desconocidos o añorados al comienzo de la narración. La búsqueda puede ser, como en El acoso, de carácter involuntario. El individuo se ve en una situación que le saca de si mismo, de su habitual enajenación, y le pone cara a cara con su pasado, y con lo que éste tiene de iluminador para el resto de su vida. La naturaleza involuntaria de dicho proceso es muy distinta a la que opera en la mémoire involuntaire proustiana, ya que en Proust el nacimiento del recuerdo ocurre con el encuentro fortuito entre la subjetividad y el objeto preñado de significados latentes; el recuerdo se desgrana paulatinamente sin que intervenga para nada el miedo, sentimiento que rompería el delicado ser de ese actus purus en que se funden la añoranza y el recuerdo. En este sentido la memoria no existe en $E l$ acoso, sino cierto proceso de confirmación de lo inevitable y de ordenación de una existencia en camino hacia la muerte. Lo que sobresale no es lo que el sujeto aporta al acto de recordar; la memoria no teje el pasado, sino que éste irrumpe en bruto, poseyéndola totalmente. ${ }^{1}$

La enajenación y el desarraigo se unen al terror como estados iniciales de la reconstitución del pasado y de la búsqueda de los orígenes,

1 La comparación "texto" - "tejido" con relación a Proust es desarrollada por Walter Berjamin en "The Image of Proust", Illuminations (New York: Schocken Books, 1969), pp. 201-15. 
de las fuentes históricas y ontogénicas del ser. Aunque, como ya se ha dicho, el tema es constante en la narrativa de Carpentier, Los peasos per. didos representa la obra más exclusivamente dedicada a definir todo aquello que caracteriza el desarraigo moderno, ubicado en este caso, dentro de la subjetividad del attista que busca sus raices perdidas en el ámbito del trópico suramericano. ${ }^{2}$ Los pasos perdidos, además, ocupa un lugar excepcional en la narrativa de Carpentier por aproximarse, más que ninguna otra de sus obras, a la creación de un personaje que, tanto en su condición de artista, como en el itinerario de su viaje, reproduce ciertos elementos significativos de la biografía de su autor. No es éste el momento de establecer las relaciones entre la novela y su germen autobiográfico, pero sí de señalar que las peripecias de su protagonista orientan al lector hacia los contornos de una vida (la de su autor) hasta ahora sólo conocida en sus detalles más externos y superficiales. ${ }^{3}$ La critica reciente ya parece sugetir dicha orientación en términos mucho más exigentes que los propuestos hasta hace sólo unos años:

A mi parecer Los pasos perdidos no es la novela que responde a las exigencias teóricas que Carpentier propone en su famoso ensayo "Problemática de la actual novela hispanoamericana". Lo que relata el narrador... son sus esfuerzos fallidos por tomar posesión mediante la palabra del continente americano. Este se le escapa porque el lenguaje polvoriento de los libros no le ofrece más que una traducción de aquello que quiere expresar... Los pasos perdidos es quizá una dramatización de las ideas contenidas en el ensayo aludido; una dramatización del acto de purificación artística y espiritual - como el del narrador de Proust- antes de comenzar la tarea de escribir la verdadera novela de América. ¿Será éste el verdadero valor autobiográfico de la obra?4

Que sea o no un fracaso la búsqueda narrada en Los pasos perdidos, y que dicho fracaso deba ser atribuido a su personaje central, manipulado irónicamente por el autor, o más aún, a éste mismo, es algo que será planteado más adelante en este análisis. Por ahora basta

2 Carpentier, Los pasos perdidos (México: Compañia General de Ediciones, 1966). En lo sucesivo se citará por esta edición.

s El autor mismo ha suministrado un breve bosquejo autobiográfico: César Leante, "Confesiones sencillas de un escritor barroco", Cuba, Año III, No. 24, abril 1964, pp. 30-33.

* Roberto González Echevarría, "Ironia, narrativa y estilo en Los pasos perdidos, de Alejo Carpentier", Nueva Narrativa Hispanoamericana, No. I (enero de 1971), pp. 117-125. 
decir que la obra, a pesar de constituir uno de los proyectos novelísticos más ambiciosos producidos por la literatura latinoamericana, no ha sido situada todavia en un contexto crítico lo suficientemente riguroso como para poder compensar la vastedad de su enfoque.

Aventura a través del tiempo y del espacio, Los pasos perdidos refleja ante todo la crisis del arte de narrar; la trayectoria hacia el Origen es la búsqueda de la posibilidad de poder narrar algo. Contratio a lo que ocurre en $E l$ acoso, el agente narrador es el que genera el acto narrativo. La distancia que media entre lo narrado y el supuesto ente que narra es distinta en ambas obras. En $\mathrm{El}$ acoso hay que suponer un "artífice" o "hacedor" situado fuera de la ficción manipulando los hilos y dejando aflorar paulatinamente la "trabazón de hechos..."' En Los pasos perdidos, hay dos distancias básicas: la que media entre el autor y esa proyección de su ser en el protagonista, sin olvidar que éste emprende, aumenta y modifica el viaje que el propio autor ha realizado con anterioridad. La segunda distancia es la existente entre el protagonista (el ente narrador) y lo escrito; ya que en el plano de la ficción el na. rrador narra lo que no hubiera podido narrar; ni cabalmente imaginar, antes de emprender el viaje $y$, más aún, lo que no pudo narrar durante el viaje. El diario que escribe es una ficción dentro de la ficción: no pudo ser escrito durante el viaje mismo por razones de tiempo y por los impedimentos materiales y prácticos que el viaje por el río y la selva crea. No hubiese podido ser escrito de ninguna manera porque entre la escritura y la experiencia media una distancia reflexiva articulada en la temporalidad y la memoria. La persistencia de dicha distancia en una obra encaminada hacia la abolición de todo aquello que se interponga entre el sujeto y la "otredad", tanto en el plano artístico como en el existencial, demuestra la esencial fragmentación del hombre como sujeto ante las cosas y ante su propio ser. Fragmentación que es temporal e ilusoriamente suspendida por medio del acto creador. Finalmente, la mutua interrelación entre el plano artístico y el existencial queda expresada en la necesidad final de regresar a la época histórica en que le toca vivir al artista y en la simultánea constatación de que todavía es posible escapar del tiempo y poder encontrar los tiempos y los pasos perdidos.

La prisión espacio-temporal y el sometimiento de ambas dimensiones a lo dictado por el hábito es el tema que primero se elabora en la obra. El protagonista se halla cerca del escenario de una representación teatral, el tiempo es allí reversible por la repetición de las mismas acciones

- Alejo Carpentier, Guerra del tiempo (México: Compañia General de Edi. ciones, 1958), pp. 183-4. 
y los mismos gestos. El recuerdo se funde con lo presente porque nada ha cambiado fuera del deterioro causado por el repetido uso de las cosas: "Por molestar menos fui a su camerino, [el de su esposa Ruth] y alli el tiempo volvió a coincidir con la fecha, pues las cosas bien pregonaban que cuatro años y siete meses no transcurrían sin romper, deslucir y marchitar. Los encajes del desenlace estaban como engrisados; el raso negro de la escena del baile había perdido la hermosa tiesura que lo hiciera sonar, en cada reverencia, como un revuelo de hojas secas. Hasta las paredes de la habitación se habían ajado, al ser tocadas siempre en los mismos lugares..." La "prisión de tablas de artificio" (10), la "Isla del Diablo" (10) que es el teatro, obliga a todos a estar o no estar en un sitio preestablecido en un momento determinado: "El miriñaque de mi esposa voló por sobre mi cabeza, pues me hallaba precisamente donde le tocara entrar, estrechándole el ya angosto paso..."(9) El tiempo vendido y el "automatismo del trabajo impuesto" (11) aísla los seres, multiplicando el tiempo de acuerdo a las funciones, "al no hallar un modo normal de hacer coincidir nuestras vidas - las horas de la actriz no son las horas del empleado- acabamos por dormir cada cual por su lado..." (11)

El teatro es la representación microcósmica de la vida moderna en la metrópoli: las "ropas inmutables" (11) de sus actores, el contrato que los rige, el estar cada uno de ellos, al igual que el protagonista, atado a su técnica ("atado a mi técnica entre relojes..." 15) es la condición del "Hombre-Avispa" del "Hombre-Ninguno" (15) cuya alma pertenece al Contable o al Cómitre. Pero el teatro también representa, en escala menor, la historia y la decadencia que el narrador ve inscritas en todo lo que lo rodea. De los comienzos felices, emprendedores y llenos de fe se pasa al automatismo y a la artificialidad. La raíz de la decadencia está precisamente en la pétdida del nexo de fe que existía entre el hombre de edades tempranas y los objetos de su culto, como señala el narrador casi al final de la obra: "Los hombres de acá ponen su orgullo en conservar tradiciones de origen olvidado, reducidas, las más de las veces, al automatismo de un reflejo colectivo - a recoger objetos de un uso desconocido, cubierto de inscripciones que dejaron de hablar hace cuarenta siglos..." (260-261) La selva revela exactamente lo contrario: "En el mundo a donde regresaré ahora, en cambio, no se hace un gesto cuyo significado se desconozca..." (261) Lo que confiere sentido a las cosas y a los actos es la fe que los inserta en la totalidad, totalidad que ya es imposible tan siquiera concebir.

- Los pasos perdidos, p. 10. 
Al "espacio cárcel" hay que agregar otro: el de las "posibilidades". Si el del teatro representaba la ejecución de los mismos actos a intervalos prefijados, este otro of rece, a primera vista, todo un panorama de alternativas, los juegos del azar y la contingencia. Es el espacio que resulta del abandono de aquel otro, donde se desarrollaban las actividades automáticas del trabajo impuesto. Cuando el trabajo cesa temporalmente y Sísifo puede gozar de sus vacaciones, éste se ve como un muñeco sin cuerda que no sabe qué hacer, "aturdido por tantas posibilidades..." (17): "Pero como el autobús tardaba demasiado en salir, acabé por andar tontamente, aturdido por tantas posibilidades, deteniéndome en la primera esquina para seguir los dibujos que sobre la acera trazaba. con tizas de colores, un lisiado con muchas medallas militares en el pecho. Reto el desaforado ritmo de mis días, liberado, por tres semanas, de la empresa nutricia que me había comprado ya varios años de vida, no sabia cómo aprovechar el ocio..." (17) La presencia del lisiado, del que goza de muy pocas alternativas y posibilidades, realza la paradójica inercia del narrador. El espacio de la ciudad es aquí laberíntico en cuanto sus numerosas puertas no conducen a nada. Al pie de una posible aventura, la voluntad del narrador queda lisiada, a merced de lo que venga.

El azar, sin embargo, se va manifestando gradualmente. Primero, la vitrina de la librería de Brentano's muestra al narrador los dos libros que más tarde irá redescubriendo en su viaje, La odiseca y el Prometheus Unbound. De igual manera ha sido el azar, o mejor una "insólita curiosidad", la que lo ha llevado a buscar en el libro de vidas de santos la identidad de San Francisco Carraciolo, para entonces ir a dar con el nombre que es anuncio de Rosario, la que será su mujer en la selva: "Pero fui a dar con unas páginas encabezadas por títulos píos: Recibe Rosa visitas del cielo, Rosa pele con el diablo, El prodigio de la imagen que suda..." (16).

Pero clato está que la ficción realza el azar negándolo: La lluvia y el refugio ofrecido por una sala de conciertos en la que se ejecuta la novena sinfonía de Beethoven que más tarde encontrará, de nuevo por azar, en la selva, afirman simultáneamente lo casual y lo causial. Alguien ha situado esa referencia, a todas luces "innecesaria", al "cadáver de algún animal muetto" " (61), en la oración que sigue aquella en que el Kappelmeister invoca el Testamento de Heiligenstadt, el mismo Kappelmeister que unas páginas más adelante recibirá tal vez la misma bala que teme recibir el narrador ("el jugador de Buffon") mientras contempla la calle sitiada por francotiradores pensando que ésta 
es un "aborrecible tablado de las posibilidades..." (68) ¿A quién, pues, además de al Herborizador Montsalvatje, habrá de agradecer el protagonista, con un "providencial alivio", la partida de Mouche?; ¿A quién, o a qué, habrá de achacarse la estratégica colocación de esa cesta de heno, derribada por un gesto brusco, que funde el recuerdo de María del Carmen con la presencia viva de la Rosario que ahora se entrega? Tal vez al Herborizador que hubo de colocarla allí.

El azar va tejiendo la "aventura", pero en lo tejido el azar acaba por desvanecerse; aunque también puede ser que la aventura sólo sea posible, como "aventura", en el Texto (textium/tejido):

Al cabo de un tiempo cuya medida escapa, ahora, a mis nociones - por una aparente brevedad de transcurso en un proceso de dilatación y recurrencia que entonces me hubiera sido insospechable- recuerdo esas gotas cayendo sobre mi piel en deleitosos al. filerazos, como si hubiesen sido la advertencia primera -ininteligible para mí, entonces- del encuentro. Encuentro trivial, en cierto modo, como son, aparentemente todos los encuentros cuyo verdadero significado sólo se revelará más tarde, en el tejído de sus implicaciones... Debemos buscar el comienzo de todo, de seguro, en la nube que reventó en lluvia aquella tarde, con tan inesperada violencia que sus truenos parecían truenos de otra latitud. (El subrayado es mío p. 19)

El tejido de las implicaciones, análogo aquí a la "trabazón de hechos" en El acoso y a "La imagen en el tapiz" de Henry James, es pura contingencia en la realidad y puro artificio en el texto.

Las coordenadas de la Aventura son múltiples. Por ejemplo: el primer capítulo, dividido en tres subcapítulos, es, siguiendo el acostumbrado procedimiento de Carpentier, una representación microcósmica de la estructura básica del libro. Como ya se ha visto, la escena inicial en el teatro es a su vez la réplica a escala menor de la decadencia histórica, desde el principio feliz hasta el presente regido por el automatismo. El título de la obra ya se anuncia en su primera página: "Como la primera noche, anduve por el soportal, oyendo la misma resonancia hueca bajo mis pasos..." (9) Paso a paso, los más de ellos fortuitos, el narrador va recorriendo un texto lleno de anticipos y de datos que más tarde serán reproducidos con sentido diferente. La "aventura 
de veinte noches" (10) "vislumbrada" (el verbo vislumbrar siempre denota el error en la obra de Carpentier) por la compañia de teatro, se transforma en cinco años de repetición continua del mismo espectáculo. La aventura del narrador, por su parte logtará ser breve, librándole del "espacio-cárcel" al que regresará no totalmente derrotado. Ruth, en su frustrado papel de trágica, será substituida por otro teatro más genuinamente trágico, durante el velorio y del padre de Rosario: "La persistencia de esa desesperación, el admirable sentido dramático con que las nueve hermanas - pues eran nueve- fueron apareciendo por 12 puerta derecha y puerta izquierda, preparando la entrada de una Madre que fue Hécuba... me hicieron sospechar que había bastante de teatro en todo ello... Y sin embargo, me sentía envuelto, arrastrado, como si todo ello despertara en mí oscuras remembranzas de ritos funerarios. .." (136).

Los anticipos abundan: el texto de las vidas de santos anuncia (como ya se ha señalado) la futura aparición de Rosario; los textos de Shelley y Homero también reaparecerán más tarde al igual que la novena sinfonía; el pintor falsificador de cuadros antiguos, conocido de Mouche, se dedica "diabólicamente" al oficio de lograr por medios fraudulentos la derrota del tiempo que el protagonista emprenderá a través de su aventura.

Por último, el museo de la universidad contiene la prefiguración del viaje, en todas sus etapas: "Y así, de peldaño en peldaño, llegaba a las vitrinas de los rascadores, hachas, cuchillos de sílex, en cuya orilla me detenía; fascinado por la noche del magdaleniense, solutrense, prechelense, sintiéndome llegado a los confines del hombre..." (39)

El primer capítulo sirve de abertura a la novela. Sin necesidad de extender la analogía con la música hasta lo excesivo, se puede decir con certidumbre que los temas fundamentales de la obra quedan enunciados en estos tres primeros subcapítulos. Lo importante, en cuanto a una definición de los procedimientos estructurales de la obra de Carpentier, es señalar el repetido juego de reflejos que se establece en ella entre lo microcósmico y lo macrocósmico. El fenómeno no se limita a las fronteras de una obra en particular sino que las va relacionando todas. Por ejemplo, si se toman tres de ellas: El acoso, Los pasos perdidos y El siglo de las luces, se verá cómo cada una de ellas refleja a la otra al igual que si se tratara de espejos. Dichos reflejos son el producto de cierta economía temática en Carpentier muy parecida a la de Borges. Piénsese en la afinidad entre la meditación de Esteban ante las Bocas del Dragón y la aventura del protagonista de Los pasos perdidos (Esteban se ve ante 
el mismo río, el Orinoco, y también habla de un regreso al Paraíso, aunque en otro contexto y con diferentes resultados).?

La entrada del narrador en Los pasos perdidos a la sala de conciertos donde está al dar comienzo una ejecución de la novena sinfonía de Beethoven, es muy parecida a la entrada del acosado, también escapán* dose de la lluvia y también en un domingo, a la sala de conciertos habanera. Lo que varía son las condiciones específicas de la situación en que vive el personaje. Aunque ha de agregarse que el narrador de Los pasos perdidos es también un acosado. Su acoso, sin embargo, es el reflejo simétricamente inverso del sufrido por el joven estudiante en La Habana de Machado. Lo que acosa al artista es la ausencia de una "trama"; de algo que estructure su vida más allá de la repetición de los gestos automáticos. $\mathrm{El}$ acoso del estudiante consiste en la apoteosis de la trama, reflejada en el encadenamiento de los signos benéficos (los del arte y la religión) y los maléficos (los del terror). Pero el paralelismo entre ambas obras no se limita a esto. La audición radial de la novena sinfonía, en "un aparato de radio, de viejísima estampa" (91), ocurrida en la selva, sirve de marco, al igual que en El acoso, para un recuento esencial de la vida del protagonista. La diferencia de estado de ánimo entre ambos protagonistas es acentuada por la distancia entre la ejecución y el oyente, como también, obviamente, por los conocimientos musicales del protagonista de Los pasos perdidos: "Pero esta noche; cerca de los leños que se rompían en pavesas, con los grillos sonando entre las vigas pardas del techo, esa remota ejecución cobraba un misterioso prestigio. Los ejecutantes sin rostros, desconocidos, invisibles, exan como expositores abstractos de lo escrito. El texto, caído al pie de estas montañas, luego de volar por sobre las cumbres, me venía de no se sabía dónde con sonoridades que no eran de notas, sino de ecos hallados en mí mismo..."(91) La distancia que va desde los ejecutantes a través del transmisor hasta el oyente, lejos de distraer causa una doble depuración: lo transmitido y lo ejecutado se evaporan y sólo queda el puro texto. En el caso del artista, sin embargo, hay otra posible distracción, la de concentrarse en la música, ya que lo dominante será el recuento autobiográfico. La partitura es el matco, a veces invisible, pero siempre presente, de la vida que se reconstituye.

7 También debemos señalar que la estructura del relato "Viaje a la semilla" aparece en Los pasos perdidos: "En fuga desaforada, los años se vaciaban, destranscutrian, se botraban, rellenando calendarios, devolviendo lunas, pasando de los siglos de tres cifras al siglo de los números. Perdió el Graal su relumbre, cayeron los clavos de la cruz, los metcaderes volvieron al templo, borróse la estrella de la natividad..." (185). 
Carpentier enmarca las experiencias más significativas del individuo en algo que se podría denominar "estado de ceremonia" o "cuadro de alegoria". La anagnórisis en la obra de Carpentier supedita su inevitable contenido psicológico al contenido de lo que rodea al individuo y que marca los límites exteriores de su conciencia. Más que una revelación interior se trata de una epifania.

De aquí que el plano "cultural" represente en Carpentier la voz dominante en relación con el plano psicológico. La noción de cultura que se deriva de su obra, en su sentido más amplio, ve en el ámbito de lo cultural una acumulación de signos, de "significantes", verdaderas fuentes simbólicas de iluminación que cada hombre necesita para poder organizar y ordenar los hechos, para poder orientarse dentro del continuo devenir de su existencia. La necesidad de este nexo cognoscitivo entre el individuo y los signos de una cultura es el tema fundamental de la obra de Carpentier. En su ensayo "De lo real maravilloso americano" Campentier ha aludido a esta necesidad sentida por él en su viaje por la China: "Pero en cuanto a mí, sé que no me bastarían los años que me quedan de existencia para llegar a un entendimiento verdadero cabal, de la cultura y de la civilización de China. Me falta, para ello, un entendimiento de los textos. De los textos que se inscriben en las estelas que sobre sus carapachos de piedra yerguen las enormes tortugas - símbolos de la longevidad, me dijeron- que pueblan, andando sin andar, tan antiguas que se les ignora la fecha del nacimiento, señoreando acequias y labrantíos, los aledaños de la gran ciudad do Pekin". ${ }^{8}$ Carpentier hace hincapié en la diferencia entre el deseo por conocer a fondo una cultura y el de la pura evasión, por muy refinadamente artística que ésta sea, al citar al comienzo de su artículo los famosos versos de "L'Invitation au Voyage": "Là tout n'est qu'ordre et beauté".. La realidad buscada no es estrictamente la del sueño y la pura belleza ansiada por Baudelaire:

La splendeur orientale, Tout y parlerait

A l'âme en secret

Sa douce langue natale.

La diferencia radica en que el viaje del poema, deseado e imaginado, es en Los pasos perdidos viaje real, aunque la imaginación lo haya

8 Carpenticr, "De io reai maravilloso americano", p. 101. 
anticipado, vivido y reelaborado a través de la memoria. En Baudelaire, el país exótico y la amada se funden, se corresponden: "Au pays qui te ressemble!" En Los pasos perdidos Mouche representa una versión degradada de este exquisito anhelo de evasiôn: "Y sin darme tiempo para enderezar el equívoco, se entregó a los grandes tópicos del anhelo de evasión, la llamada de lo desconocido, los encuentros fortuitos, en un tono que algo debía a los Sirgadores Flechados y las Increíbles Floridas del Barco Ebrio..." (35)

Pero es precisamente Mouche la que menos podrá ajustarse al nuevo ambiente de la selva: "Mouche, en cambio, iba resultando tremendamente forastera dentro de un creciente desajuste entre su persona y cuanto nos circundaba. Un aura de exotismo se espesaba en torno a ella, estableciendo distancias entre su figura y las demás figuras..." (112) La falta de acoplamiento con la realidad de la selva por parte de Mouche es doble; su cuerpo se deteriora progresivamente y su imaginación, viciada por lo libresco, precluye todo posible contacto entre ella y lo "real-maravilloso". El sentido de ajuste es visto como algo más allá de lo cultural o de lo orgánico (orgánico en cuanto la selva rechaza a Mouche como ciertos organismos rechazan un cuerpo extraño). En fin, la percepción decisiva del acoplamiento entre personaje y medio ambiente es estético-cultural. Rosario encarna la sintesis entre la relación mencionada por Baudelaire ("au pays qui te ressemble"), que es primordialmente estética, y los niveles culturales y orgánicos, muy presentes en la imaginación del narrador carpentereano. La manera estética con que el narrador percibe a Rosario es el ejemplo más exacto de la tendencia (descrita anteriormente) de enmarcar los estados de ánimo $y$ los personajes:

Rosario... era como la Cecilia o la Lucía que vuelve a engastarse en sus cristales cuando termina de restaurarse un vitral. De la mañana a la tarde y de la tarde a la noche se hacía más auténtica, más verdadera, más cabalmente dibujada en un paisaje que fijaba sus constantes a medida que nos acercábamos al tío. Entre su carne y la tierra que se pisaba se establecían relaciones escritas en las pieles ensombrecidas por la luz, en la semejanza de las cabelleras visibles, en la unidad de formas que daba a los talles, a los hom. bros, a los muslos que aquí se alababan, una factura común de obra salida de un mismo torno. (112-13).

Al "tejido de implicaciones" que el narrador ve en los juegos del azar que paulatinamẹnte dạn forma a su "aventura" se une este otro 
"tejido" o texto, el de las relaciones entre culturas. Rosario ingresa en la tradición europea a través de las figuras de las santas Cecilia y Lucia, precisamente en el momento en el cual se describe la manera perfecta con que encaja en su ambiente. La alusión trasciende el plano de lo litúrgico-religioso, ya que, por sólo citar dos ejemplos, Rafael dedicó un famoso cuadro a la santa, patrona de la música, y Mallarmé un poema, "Sainte", donde la santa aparece en su vitral:

\section{A ce vitrage d'ostensoir}

Que frôle une harpe par l'Ange

Formée avec son vol du soir

Pour la délicate phalange

Du doigt que, sans le vieux santal

$\mathrm{Ni}$ le vieux livre, elle balance

Sur le plumage instrumental,

Musicienne du silence. ${ }^{9}$

Las percepciones del narrador siempre remiten a otra tradición, lo que busca es poder transitar de una a otra, o la mutua iluminación de ambas. El contexto es estético y hasta libresco, como cuando se compara, o mejor, se compagina, la travesía por el río con lo escrito hace años por fray Servando de Castillejos. ${ }^{10}$ Aunque el narrador persista en reclamar ese contacto directo establecido con "lo real", la distancia artís. tica es lo que prima. En la dialéctica de lo real-maravilloso siempre hay más maravilla que realidad, más texto que presencia. El impulso estético es aproximación, pero también distancia; y la cultura es, a la vez, la sintaxis que hace posible la aproximación entre los hombres y lo que los separa a veces irreparablemente. $L_{a}$ proximidad entre el cuerpo de Rosario y el del narrador hace patente dicha distancia:

No eran tan sólo botellas las que se alzaban ahí, en barrera de vidrio que imponía cuidado a las manos: eran los mil libros leídos por mí, ignotados por ella; eran creencias de ella, costumbres, supersticiones, nociones, que yo desconocía y que, sin embargo, alentaban razones de vivir tan válidas como las mías.

9 Stephane Mallarmé, Oeuvres Complètes (Paris: Gallimard, 1945), p. 53.

10 Ver: Raúl Silva Cáceres, "Una novela de Alejo Carpentier", Mundo Nuevo, No. 17 (noviembre 1967), p. 35. El crítico ha dado con la verdadera fuente, se trata de El Orinoco ilustrado de José Gumilla, obra que data de mediados del siglo xvitt. 
Mi formación, sus prejuicios, lo que le habían enseñado, lo que sobre ella pesaba, eran otros tantos factores que, en aquel mo. mento, me parecían inconciliables. Me repetía a mí mismo que nada de esto tenía que ver con el siempre posible acoplamiento de un cuerpo de hombre y un cuerpo de mujer, y, no obstante, reconocia que toda una cultura, con sus deformaciones y exigencias, me separaba de esa frente detrás de la cual no debía haber siquiera una noción muy clara de la redondez de la tierra, ni de la disposición de los países sobre el mapa. (113)

El tejido de esta aventura es diferente del que habitualmente sirve de base para las novelas de aventuras. El narrador reconoce que su his. toria es "pobre" en cuanto a "peligros arrostrados" (217) pero que, en cambio, ha encontrado en todos los lugares del viaje "la solicitación inte. ligente" y "el motivo de meditación" sobre el arte, la poesía y los mitos, que le han sido "más instructivos para comprender al hombre que cientos de libros escritos en las bibliotecas por hombres jactanciosos de conocer al Hombre..." (217) Sólo el conocimiento del hombre a través del arte de narrar da forma y sentido a la Aventura.

La dialéctica entre el Azar y la Aventura es la piedra angular de toda la arquitectura narrativa de Los pasos perdidos. El Azar tiene un doble significado en la obra: designa lo cático y lo contingente, la irracionalidad que está (como el reverso de la moneda) del otro lado del Orden de la sociedad moderna. En ésta, el orden aparente de las cosas es sólo funcional, sin que por necesidad sus objetivos sean beneficiosos para el hombre. El orden de las cosas obliga al hombre a convertirse en personaje y a trazar el dibujo y la trayectoria de una acción ya de antemano estipulada en los diferentes contratos que firma. La insistencia en las primeras páginas de Los pasos perdidos sobre las ataduras establecidas por los contratos revela que los personajes son lo estipulado en estos contratos. ${ }^{11}$ Visto desde esta perspectiva enajenada, el azar es el terror. Se es algo o se cae en el vacío, en la anarquía caótica del ser que se sabe nulo por el hábito de sólo ser su función. Dicha función, sin embargo, lo conviette en otra nulidad, la de ser sólo un eslabón de la cadena de operaciones a que pertenece; pieza reempla. zable cuando se gasta.

11 "No le faltaban ganas [a Ruth] de romper el contrato..." (10-11); "de una obligación contraída en el instante de estampar su firma al pie de nuestro contrato matrimonial..." (11); "fui llevado al despacho del Rector, que me hizo firmar un contrato..." (38) 
La coherencia añorada no es la impuesta por el trabajo alienado. Lo que se busca es el arquetipo de un mundo coherente y civilizado cuyo modelo histórico básico fue, precisamente, la ciudad o polis con sus leyes y sus obras. ${ }^{12} \mathrm{La}$ individualidad fragmentada huye del orden viciado y del azar; su única salida es el viaje hacia otros espacios o la Aventura. La Aventura es "azarosa", pero (una vez hecha ficción) coherente: un verdadero manantial de significados.

El otro significado del azar comienza a vislumbrarse durante la reunión en el piso de Mouche. Los miembros del grupo bohemio allí reunidos repiten los lugares comunes propios de la eterna vanguardia artística y los de "el baratillo surrealista" (29). La astrología y el azar son los temas favoritos. El azar es interpretado como parte integral del proceso de creación artística; o mejor, de su anulación: "La música verdadera es una mera especulación sobre frecuencias, decía mi asistente grabador, arrojando sus dados chinos sobre el piano, para mostrar cómo podía conseguirse un tema musical por el azar..." (33) El personaje X.T.H., cuyo nombre sugiere la idea de tres signos combinados por el azar, desempeña el papel paródico del tábano socrático, siendo el encargado de someter al grupo a una especie de terapéutica existencial que consiste en detener las acciones de los demás en cualquier momento dado: "Y a gritos hablábamos todos cuando un ' $¡ H$ Halt!' enérgico, arrojado desde la entrada, por una voz de bajo, inmovilizó a cada cual, como figura de museo de cera..., en el gesto de devolver una bocanada de humo..." (33). Actuar de modo automático, según Extieich, es ser "esencia sin existencia..." (33) La validez del diagnóstico de Extieich no es cancelada por la obvia ironía con que el narrador ve su terapéutica y la filosofía manoseada en la cual se basa. El procedimiento de Extieich demuestra que la artificialidad y el automatismo de la vida mo. derna se asemejan a una cinta de celuloide. Extieich es el proyeccionista, que detiene la cinta. El contexto en que ocurre el episodio da validez a esta analogía, ya que el narrador se dedica a la cinematografía y la reunión misma en que se hallan todos celebra el estreno de una de sus películas. El sentido más literal de la esclavitud del hombre por su técnica ("Atado a mi técnica entre relojes, cronógrafos, metrónomos...", 15) radica en que el personaje deba reproducir a través de su propia vida la sucesión automática de una imagen tras otra. La realidad hecha cinta pierde toda substancia ontológica.

12 Al respecto Octavio Paz ha señalado: "En la antigüedad el universo tenia una forma y un centro; su movimiento estaba regido por un ritmo cíclico y esa figura rítmica fue durante siglos el arquetipo de la ciudad, las leyes y sus obras..." Ver: El arco y la lira (México: Fondo de Cultura Económica, 1967), p. 260. 
Por otra parte, la noción vulgar del papel desempeñado por el Azar en la creación artística, no ocurre en el texto sólo con valor satírico, sino que refleja quizás el estrato más profundo de Los pasos perdidos en cuanto a un planteamiento de lo que significa el arte de narrar.

El lector no debe atribuir a los caprichos del azar que el " Halt!" de Extieich se produzca inmediatamente después de que se mencionen los dados chinos. El narrador es sorprendido en el momento mismo en que piensa sobre los dados chinos y el poema de Mallarmé "Un coup de dés": "('Yo soy yo. Estoy sentado en un diván. Iba a rascar un fósforo sobre el esmeril de la caja. Los dados de Hugo me habian recordado el verso de Mallarmé. Pero mis manos iban a encender un fósforo sin mandato de mi conciencia. Luego, estaba dormido. Dormido como todos los que me rodean.')" (33).

El poema "Un coup de dés" articula la preocupación de Mallarmé por la poesía como el único medio posible de reconciliar el lenguaje con lo absoluto. El proyecto de Mallarmé es el más ambicioso en la poesía moderna. ${ }^{13}$ Pero lo importante aquí es desplazarse de las cuestiones planteadas por él en "Un coup de dés", a una problemática muy parecida y de mayor valor para el análisis de Los pasos perdidos: la planteada por Borges en su cuento "La loteria de Babilonia".

El carácter conspiratorio de muchas de las empresas ficticias descritas por Borges en cuentos como "Tlön, Uqbar, Orbis Tertius" y en "La lotería de Babilonia" alude a la necesidad en el hombre por vivir del orden, por escapar el caos del azar. La "tenebrosa corporación" babilónica hace del azar una institución. Su propósito inicial es, sin embargo, negar el accidente, pero para negarlo habrá de asumirlo, habrá de hacer de lo contingente un sistema; lo cual es análogo a la pretensión que hace al hombre construir ficciones: sustituir el accidente por el orden, el caos por la aventura:

Bajo el influjo bienhechor de la Compañía, nuestras costumbres están saturadas de azar. El comprador de una docena de ánforas de vino damasceno no se maravillará si una de ellas encierra un talismán o una víbora; el escribano que redacta un contrato no deja casi nunca de introducir algún dato erróneo; yo mismo, en esta apresurada declaración, he falseado algún esplendor, alguna atrocidad. Quizá, también, alguna misteriosa monotonía... Nuestros historiadores, que son los más perspicaces del orbe, han inven.

13 Para una interpretación del poema ver: Octavio Paz, El arco y la lird, pp. $270-75$. 
tado un método para corregir el azar; es fama que las operaciones de ese método son (en general) fidedignas; aunque, naturalmente, no se divulgan sin alguna dosis de engaño. Por lo demás, nada tan contaminado de ficción como la historia de la Compañia... ${ }^{14}$

El narrador de "La lotería de Babilonia" está situado en dos planos de la temporalidad radicalmente distintos el uno del otro. Su voz nace, más que de la experiencia milenaria, del vivir en lo eterno o en lo que eternamente se repite: "Como todos los hombres de Babilonia, he sido procónsul; como todos, esclavo; también he conocido la omnipotencia, e] oprobio, las cárceles..." 15 Pero, al mismo tiempo, su voz surge de una situación muy precisa: "Poco tiempo me queda; nos avisan que la nave está por zarpar..." La voz narra ciesde la situación que Carpentier define en $E l$ acoso como un modo de "vivir en lo después".". Dicha situación es la de la partida, la del comienzo de un viaje, viaje único y viaje arquetípico. Narrar desde esa situación implica el tener que hacer una "apresurada declaración".18 Borges crea un tipo de narrador que debiera de poseer todo el tiempo posible, el infinito, para narrar lo infinito, pero, a la vez, le niega la oportunidad de hacerlo. La "declaración" queda viciada en su verdad, o mejor, su verdad se multiplica en verdades que se niegan mutuamente. He aquí, a todas luces, esa "infinita y plástica ambigüedad" que ve Borges como elemento constitutivo de la experiencia personal. ${ }^{19} \mathrm{La}$ ficción of rece la posibilidad de escuchar la voz de la infinita experiencia, pero sólo le concede al personaje unos minutos para contar lo infinito, de aquí que éste sólo pueda expresarse, a través de la ambigüedad y la siembra de dudas y paradojas en la mente del lector que anhela librarse de los avatares del azar a través de la palabra.

Contrario a Mallarmé, Borges nunca pretendería crear, o haber creado, una obra abierta hacia lo infinito. Lo que se reproduce incesantemente en sus ficciones es el infinito empeño por lograr lo infinito. Sólo

\footnotetext{
14 Borges, "La lotería de Babilonia", Obras completas, II, p. 74.

15 Ibid., p. 67.

16 Ibid., p. 72.

17 "Los parientes y amigos que lo rodean y pronto lo acompañarán a la esta. ción han dejado, esta mañana, de moverse en el presente. Sus voces le llegan de lejos; de un ayer que se abandona. No escucha sus consejos, por gozarse mejor del indefinible deleite de sentirse ya en un futuro imprevisto.." El acoso, Guerra del tiempo, op. cit., p. 179.

18 Borges, p. 74 .

1. Luis Harss, Los nuestros (Buenos Aires: Edditorial Sudamericana, 1966), p. 151.
} 
que, para él, el empeño de crear ficciones totales siempre evoca la totalidad, pero sólo para negar la posibilidad de alcanzarla.

El infinito también está presente en Los pasos perdidos, y su presencia y la del azar se relacionan. La angosta puerta que posibilita el tránsito del río a Santa Mónica de los Venados a través de la parte más densa de la selva, está marcada con los signos de lo inifinito: "Ha. bía, a dos metros de nosotros, un tronco igual a todos los demás: ni más ancho, ni más escamoso. Pero en su corteza se estampaba una señal semejante a tres letras $\mathrm{V}$ superpuestas verticalmente, de tal modo que una penetraba dentro de la otra, una sirviendo de vaso a la segunda, en un diseño que hubiera podido repetirse hasta el infinito..." (166) Los signos encajan sirviéndose de vaso el uno al otro como la reflexión producida por dos espejos situados frente a frente. La imagen anticipa el juego de espejos que se producirái una vez dentro del túnel: "Al cabo de algún tiempo de navegación en aquel caño secreto, se producía un fenómeno parecido al que conocen los montañeses extraviados en las nieves: se perdía la noción de la verticalidad, dentro de una suerte de desorientación, de mareo de los ojos. No se sabía ya lo que era del árbol y lo que era del reflejo. No se sabía ya si la claridad venía de abajo o de arriba..." (167-8) Más tarde, casi al final de la novela la búsqueda de la puerta que permitirá el regreso a Santa Mónica de los Venados, repite el encuentro con lo infinito: "Con la vista fija en los troncos, busco, a la altura del pecho de un hombre que estuviera de pie sobre el agua, la incisión que dibuja tres $\mathrm{V}$ superpuestas verticalmente, en un signo que pudiera alargarse hasta el infinito..." (277) La búsqueda hace patente de nuevo la presencia del "aborrecible tablado de las posibilidades" (68) que hubo de confrontar el narrador en la calle acechada por francotiradores, sólo que en esta ocasión, las posibilidades, la cara proteica del azar, sería señal de salvación y no de muerte: "Al fin, por decir algo, me señala unos árboles, idénticos a los demás, preguntándome si la entrada no sería por aquí. 'Es posible', le respondo, sabiendo que ahí no hay señal alguna..." (278) La respuesta de Simón cierra el juicio que se iniciara cuando el protagonista entró en la oficina del curador: "Posible no es palabra de tribunal..." (278), dice Simón a aquel que, llevado al fin de su viaje por "lo hecho posible", por el abrirse unas tras otras las posibilidades, llegó a creer demasiado en ellas, y sobre todo en la más difícil de todas, la posibilidad de desandar lo andado: "la marcha por los caminos excep. cionales se emprende inconscientemente, sin tener la sensación de lo maravilloso en el instante de vivirlo: se llega tan lejos, más allá de lo 
trillado, más allá de lo repartido, que el hombre, envanecido por los privilegios de lo descubierto, se siente capaz de repetir la hazaña cuando se lo proponga - dueño del rumbo negado a los demás-. Un día comete el irreparable error de desandar lo andado..." (280) $\mathrm{El}$ instante mismo de comprobar el cierre de las posibilidades, o mejor, de esta posibilidad es en sí fortuito: " $P$ osible no es palabra de tribunal', comenta el otro, sentencioso, y al punto caigo sobre una borda de la barca, que ha ido a meterse, de proa, en una red de lianas..." (278) El remo en el agua que sirve de palanca para echar la canoa atrás revela la profundidad del río, profundidad que existe en ese "ahora" porque "Ha llovido fuera de estación..." (276). Pero las aguas han de bajar y el juego infinito de las posibilidades tal vez hará posible que otro emprenda la búsqueda de los pasos perdidos: "En cierto tronco escamado, tronco de un ocre manchado de verde claro, empieza a verse, cuando la corriente se aclara, el Signo dibujado en la corteza, a punta de cuchillo, unos tres palmos bajo el nivel de las aguas." (286) El cierre de la novela coincide con la lenta apertura de una puerta que se abre más hacia el tiempo que hacia el espacio. El presente desde el cual se narra la oración final no es el del testigo, es el tiempo de la imaginación que ve renacer, para otra, las posibilidades anunciadas por el regreso de los signos. Es el tiempo que está más allá de la "aventura", pero que señala la posibilidad de aventura para el Otro.

En un pasaje ya anteriormente citado, el narrador de Los pasos perdidos se habla a sí mismo: "me digo que la marcha por los caminos excepcionales se emprende inconscientemente, sin la sensación de lo maravilloso en el instante de vivirlo..." (280) De la maravilla del azar se pasa a la narración de la "aventura"; narrar la aventura, sin em. bargo, obliga a comenzar no por su principio sino por su final. El co. mienzo sólo es "imaginable" a partir del Final. La narración mantendrá por todos los medios posibles la ilusión de que lo ocurrido está ocurriendo. Pero, aun así, cuando el narrador dice: "debemos buscar el comienzo de todo..." (19), se sabe que en la vida no hay verdaderos comienzos. Encontrar el comienzo ya es ganarle la partida a la contingencia, al azar. De la vida como crónica se pasa a la vida como ficción: "Había grandes lagunas de semanas y semanas en la crónica de mi propio existir; temporadas que no me dejaban un recuerdo válido, la huella de una sensación excepcional, una emoción duradera..." (14). Los pasos perdidos narra el tránsito de la crónica a la ficción, del vacío a la aventura. La aventura representa el tiempo en el cual todo concuerda 
y adquiere sentido. Se trata de algo similar a la aventure a que se refiere Roquetin en La nausée de Jean Paul Sartre.

Para Roquetin, narrador de La nausée de Sartre, la aventura repre. senta el tiempo preñado de significación, el Karios, en lugar del mero devenir o Cronos. ${ }^{20} \mathrm{La}$ aventura encadena los momentos, establece y relaciona los comienzos y los finales. El tiempo se hace evento y la in. forme crónica del existir se organiza, cobra forma. Hay que escoger entre vivir o contar: ("Mais il faut choisir: vivre on raconter"), ${ }^{21}$ contar lo cambia todo. Se vive en la contingencia, pero

quand on raconte la vie, tout change; seulement c'est un changement que personne ne remarque: la preuve c'est qu'on parle d'his. toires vraies. Comme s'il pouvait y avoir des histoires vraies; les événements se produisent dans un sens et nous les racontons en sens inverse. On a l'air de débuter par le commencement: 'C'était par un beau soir de l'automne de 1922. J'étais clerc de notaire à Marommes.' Et en réalité c'est par la fin qu'on a commencé. Elle est lá, invisible et présente, c'est elle qui donne à ces quelques mots la pompe et la valeur d'un commencement... Mais la fin est là, qui transforme tout. Pour nous, le type est déjà le héros de l'histoire. Sa morosité, ses ennuis d'argent sont bien plus précieux que les nôtres, ils sont tout dorés par la lumière des passions futures. Et le récit se poursuit à l'envers: les instants ont cessé de s'empiler au petit bonheur les uns sur les autres, ils sont happés par la fin de l'histoire qui les attire et chacun d'eux attire à son tour l'instant que le précède... Nous oublions que l'avenir n'était pas encore là; le type se promenait dans une nuit sans présages, qui lui offrait pêle-mêle ses richesses monotones et il ne choisissait pas. J'ai voulu que les moments de ma vie se suivent et s'ordonnent comme ceux d'une vie qu'on se rappelle. Autant vaudrait tenter d'attraper le temps par la queue. ${ }^{22}$

Atrapar al tiempo por la cola es la ilusión de haber derrotado el azar. El acto imaginativo plasmado en la letra o en el canto hace de. esta ilusión un hecho transmisible y duradero. Hasta hoy el arte, y sobre todo $l_{a}$ ficción, han sido el antídoto más persistente, aunque no

\footnotetext{
2o Los dos términos pertenecen a la exégesis bíblica, pero han sido recientemente aplicados al estudio de la ficción por Frank Kermode, The Sense of an Ending (New York: Oxford University Press, 1966).

21 Jean-Paul Sartre, La nausée (París: Gallimard, 1938), p. 57.

22 Ibid., pp. 58-59.
} 
del todo efectivo, del accidente. Lo fortuito y lo contingente ingresan en la estructura de la ficción ya en una especie de pasado, o en un tiempo que existe para explicarlos. Por ejemplo, pocas cosas hay que denoten más la presencia del azar que una caída. Caer nos aguarda, o puede aguardarnos, al final de cada paso, o de cada movimiento, y aun, en mitad de ellos; surge como del reverso de nuestros gestos. Disper. sas en el texto de Los pasos perdidos hay tres caídas que por su colocación y por la indagación que provocan, parecen ser la clave más secreta de que se vale la obra para designar los juegos del azar.

$\mathrm{L}_{\mathrm{a}}$ primera de ellas ocurre apenas empezada la novela. El narrador se halla cerca del escenario del tiempo repetido cuando ocurre uno de los tantos hechos prescritos en el libreto de la representación: "A tiempo salí de la luz, pues sonó el disparo del cazador y un pájaro cayó en escena desde el segundo tercio de bambalinas..." (9) La segunda ocurre inmediatamente después de concluir la transmisión radial de la novena sinfonía: "Me asomo a una ventana: los árboles más próximos se han perdido en $l_{a}$ niebla. El ganso del traspatio desenvaina la cabeza de bajo el ala y entreabre el pico, sin acabar de despertarse. En la noche ha caído un fruto..." (103) La caída fortuita de un fruto sigue a la ejecución de aquello que ha sido descrito anteriormente como el triunfo de la medida y de la precisión sobre el caos: "Siempre que yo veía co. locarse los instrumentos de una orquesta sinfónica tras de sus atriles, sentía una aguda expectación del instante en que el tiempo dejara de acarrear sonidos incoherentes para verse encuadrado, organizado, sometido a una previa voluntad humana, que hablaba por los gestos del Medidor de su Transcurso..." (19)

Sin embargo, el hecho fortuito de la caída del fruto, posible anuncio de un tiempo y un espacio que se abren hacia la riesgosa pero bené. fica libertad de la aventura, ocurre, en la ficción, precisamente alli, al final de ese capítulo, como el punto o acto que lo cierra. El azar es inmediatamente asimilado por el orden. La tercera caída ocurre en la imaginación del narrador, cuando éste repasa mentalmente la caída de un árbol milenario:

A veces, luego de varios siglos de vida, uno de esos árboles perdía las hojas, secaba sus líquenes, apagaba sus orquídeas. Las maderas le encanecían, tomando consistencia de granito rosa, y quedaba erguido, con su ramazón monumental en silenciosa desnudez, revelando las leyes de una arquitectura casi mineral, que tenía simetrías, ritmos, equilibrios, de cristalizaciones. Chorreando por 
las lluvias, inmóvil en las tempestades, permanecía allí, durante algunos siglos más, hasta que, un buen día, el rayo acababa de derribarlo sobre el deleznable mundo de abajo. Entonces, el coloso, nunca salido de la prehistoria, acababa por desplomarse, aullando por todas las astillas, arrojando palos a los cuatro vientos, rajado en dos, lleno de carbón y de fuego celestial, para mejor romper y quemar tado lo que estaba a sus pies. Cien árboles perecian en su caída, aplastados, derribados, desgajados, tirando de lianas que, al reventar, se disparaban hacia el cielo como cuerdas de arcos. Y acababa por yacer sobre el humus milenario de la selva, sa. cando de la tierra unas raíces tan intrincadas $y$ vastas que dos caños, siempre ajenos, se veían unidos, de pronto, por la extracción de aquellos arados profundos que salían de sus tinieblas des. trozando nidos de termes, abriendo cráteres a los que acudian corriendo, con la lengua melosa y los garfios de fuera, los lamedores de hormigas. (171-72)

La caída evocada en la mente cierra la progresión caida del pájano, del fruto $y$ del árbol. Interpretada al nivel más abstracto, dicha progresión representaría el tránsito del tiempo prisión (caída del pájaro en escena) a un tiempo ya en vías de ser ámbito liberador. Dicho tiempo comienza al concluir la sinfonía escuchada en la selva, acto catático mediante el cual el narrador salda cuentas con su pasado y (a través de la novena sinfonía de Beethoven) con las realidades de la cultura occidental. La catarsis ya ha sido anunciada en el epígrafe (extraído de El Libro de (bilam-Balam) que encabeza el capítulo en cuestión: ". . será el tiempo en que tome camino, en que desate su rostro y hable y vomite lo que tragó y suelte su sobrecarga." (81) La caída del fruto (al concluir la sinfonía y que sirve de cierre al subcapítulo) realza el comienzo del tiempo preñado de posibilidades benéficas, reverso exacto del tiempo paralizante de la ciudad con su caótica plenitud de alternativas enajenantes. Más tarde la caída del árbol surgirá precisamente no de un hecho presenciado por el narrador, sino de su imaginación. Al nivel de la ficción este acto imaginativo confirma la creciente fertilidad creadora del protagonista. ${ }^{23}$

23 En un artículo de próxima aparición Roberto González Echeverria prueba que gran parte de los episodios en la selva Carpentier los tomó del libro, Reisen in British-Guiana Su* Den Jobren 1840-1844, publicado en Leipzig en 1847, del explorador alemán Richard Schomburg. Entre los episodios que Carpentier calcó de este oscuro libro se encuentra el de la caída del árbol. Lo que a nivel de la ficción se da como un acto puro de la imaginación remite finalmente a las fuentes textuales que, al parecer, representan el elemento más constitutivo del proceder 
Desde el punto de vista del tema del azar, la progresión conduce es. trictamente de la artificial repetición ocurrida todos los días en una "prisión de tablas" (caída del pájaro en escena), a la repetición de algo (caída del fruto en la selva) que ocurre centenares de veces todos los días, pero que cada vez que ocurre produce en nosotros, si es que nos detenemos a pensar en ello, sentimientos contradictorios: de un lado la leve sorpresa causada por no poder atribuir su ocurrencia a ninguna voluntad sino al azar; y del otro, a pesar de nuestra sorpresa, el convencimiento de que aquello no ha sido un accidente sino el re. sultado no tanto del encadenamiento de las causas, sino más bien de la habitual manera de proceder del reino natural, que lo hace todo "tan puntualmente". La caída del árbol sólo agranda un poco las escalas convirtiendo el proceder del cosmos y de la naturaleza en algo vasto, el ritmo de lo cotidiano es sustituido por su repetición a través de los siglos, a cuya escala la caída del árbol milenario casi no llega a equivaler a la caída del fruto en uno de nuestros tantos días. Es esta precisamente la noción con que se inicia el proceso mediante el cual el lector unirá en su memoria las tres caídas. Noción que surge del con. traste entre las diferentes escalas temporales representadas por las tres caídas. La posibilidad del acto interpretativo es sólo una de tantas otras operaciones que la ficción solicita a medida que progresa; operaciones causadas por esa especie de simpatía o, tal vez, de desmedida ambición, que sentimos a instancias de la ficción misma, y que nos mueve a concebir al libro, y en él al mundo, como el juego de espejos en que el azar se manifiesta y se evapora en un mismo acto.

\section{II}

Desde la perspectiva sartreana Los pasos perdidos es la quintaesen. cia de la aventura. Como se verá a continuación, el esquema temporal de la novela revela el cuidadoso arreglo de fechas y de días que sirve de andamiaje a la aventura emprendida por su protagonista. Sabemos que Carpentier realizó su viaje por el Orinoco en 1947, y que la novela fue publicada en $1953 .^{24}$ Sin embargo, se puede establecer con bastante certeza $(y$, sobre todo, con resultados esclarecedores en cuanto al aná.

novelístico seguido por Carpentier. La aproximación textual a la realidad llamada por muchos "realismo mágico", se relaciona con lo real sólo a través de 12 radical mediación de otros textos.

Q4 Klaus Müller-Bergh, "Alejo Carpentier: autor y obra en su época", Revista Iberoamericana, No. 63 (enero-junio, 1967), p. 20. 
lisis) que el viaje narrado en la novela ocurre en el año de 1950, co. menzando el domingo 4 de junio y dando fin el sábado 30 de diciembre del mismo año. ${ }^{25}$ La ficción incluye treinta de los últimos treinta y un domingos del año a partir del primer domingo del sexto mes (junio), o sea, del mes axial que marca la mitad del año. 1950 es, por otra parte, el comienzo de la segunda mitad del siglo, de aquí que tanto el mes como el año durante los cuales transcurte la ficción, deban ser considerados como fronteras, puntos de demarcación entre las dos mitades (del año y del siglo); momentos en que el comienzo y el final se tocan.

Como ya se ha señalado, la ficción abarca treinta de los últimos treinta y un domingos del año (del domingo 4 de junio al sábado 30 de diciembre), y por ende el resto de los días de la semana treinta veces cada uno. El último domingo del año, excluido le la ficción, comple. taría un ciclo análogo al mes más largo, es decir el mes de treinta y un días. Al mismo tiempo, el año de 1950 se cierra en un domingo, fin de semana y fin de año coinciden.

El domingo es designado desde el comienzo de la novela como el "último día": "Pero otra vez un texto, un escenario, una distancia, se interponia entre nuestros cuerpos, que no volvían a encontrar ya, en la Convivencia del Séptimo Día, la alegría de los acoplamientos primeros..." (18) El lunes es el día más temido, el día en que Sísifo co. mienza a subir la cuesta una vez más. La semana, como la serpiente que se muerde la cola (cola-domingo, lunes-boca), es la eterna rueda que repite la necesidad de desempeñar las mismas tareas sin sentido: "Pero la calle me fue particularmente triste en esta noche de domingo, ya temerosa de las angustias del lunes..." (36) Más tarde, en la selva, el narrador olvidará que el 12 de junio es lunes y no martes, olvido que anuncia el comienzo de su liberación. ${ }^{26}$

Desde el comienzo los días de la semana se presentan en la con. ciencia del narrador como entidades estables de su cultura, es decir, como el producto de los ritmos de sus labores y descansos. La apariencia de cada día de la semana está como escondida y presente a la vez en todos sus rasgos y detalles. Los días de la semana, y en especial los dos más señalados en la sociedad industrial moderna, el domingo y el

25 The World Almanac 1949 (New York: New York World-Telegram, 1949), p. 769.1950 es el año más cercano al viaje emprendido por Carpentier y a la composición de la novela, cuyas fechas concuerden con las dadas en Los pasos perdidos. Por otra parte, el año es rico en posibilidades alegóricas, aprovechadas en lo sumo por el narrador.

26 El olvido ya ha sido explicado por Roberto Gonzalez Echeverria, "Ironía y estilo narrativo en Los pasos perdidos, de Alejo Carpentier", Nueva Narrativa Hispanoamericana, No. 1 (enero de 1971), p. 119. 
lunes, pertenecen a esa capa cultural que se interpone entre la mirada del hombre y las cosas, o entre el hombre y "sus" cosas, ya que es precisamente por haberlas hecho suyas que le es imposible al hombre verlas en el estado esencial de cosa-en sí. El olvido del lunes por parte del natrador de Los pasos perdidos es el teverso exacto de la "presencia" del domingo experimentada por Roquetin en La nausée; la mañana dominical se le hace patente a éste de manera irreductible, imposible de explicar:

J'avais oublié, ce matin, que c'était dimanche. Je suis sorti et je suis allé par les rues comme d'habitude. J'avais emporté Eugénie Grandet. Et puis, tout à coup, comme je poussais la grille du jardin public, $j$ 'ai eu l'impression que quelque chose the faisait signe. Le jardin était desert et nu. Mais... comment dire? Il n'avait pas son aspect ordinaire, il me souriait. Je suis resté un moment appuyé contre la grille et puis, brusquement j'ai compris que c'était dimanche. C'était là sur les arbres, sur les pelouses comme un léger sourire. Ça ne pouvait pas se décrire, il aurait fallu prononcer trés vite: C'est un jardin public, l'hiver, un matin de dimanche. ${ }^{27}$

En Los pasos perdidos, la fuerza del azar, convertida en designio dentro de la ficción, ha repartido los hechos centrales de la trama de acuerdo a un esquema basado en los días de la semana. El domingo del comienzo de la novela representa la ruptura del hábito, el comienzo de las vacaciones ya de antemano vacías. El domingo siguiente es cuando el personaje escucha la sinfonía por la radio, justamente una semana después de no haber querido escucharla al encontrarse fortuitamente con ella en la sala de conciertos de la metrópoli. El mismo domingo del comienzo cuando, al abandonar la reunión en el piso de Mouche, sin saber qué hacer, se viera en una "noche de domingo, ya temerosa de las angustias del lunes..." (36) El segundo domingo, en cambio, ya le halla en camino de poder olvidar que el dia siguiente será lunes.

El domingo dieciocho (tercer domingo de la ficción —apuntado en el diario como lunes) se añade a los dos domingos anteriores como fecha clave, ya que durante él ocurren dos hechos de suma importancia en la búsqueda de los pasos perdidos: el regreso de Mouche, que libera al protagonista de una carga molesta que arrastraba desde "allá", y la entrada por la puerta grabada con las tres V, inicio del viaje hacia

27 Jean-Paul Sartre, La nauséel (Paris Gallimard: 1938), p. 59. 
Santa Mónica de los Venados. A estos dos hechos se podría agregar el de la unión sexual entre Rosario y el narrador, opuesto exacto de aquella "Convivencia del Séptimo Día" mencionada el domingo del comienzo. El encuentro sexual culmina con la pronunciación sacramental del nombre propio. El protagonista es bautizado por Rosario: "Hoy, por primera vez, Rosario me ha llamado por mi nombre, repitiéndolo mucho, como si sus sílabas tuvieran que tornar a ser modeladas-y mi nombre, en su boca, ha cobrado una sonoridad tan singular, tan inesperada, que me siento como ensalmado por la palabra que más conozco, al oírla tan nueva como si acabara de ser creada..." (162) El bautizo del domingo es seguido por el nacimiento simbólico ocurrido el lunes (martes en el diario). La novela adopta aquí una forma parecida a la del "Viaje a la semilla"; sólo que esta vez el individuo va del bautizo a un nacimiento que es un renacer:

Perdida toda razón, incapaz de sobreponerme al miedo, me abrazo de Rosario, buscando el calor de su cuerpo, no ya con gesto de amante, sino de niño que se cuelga del cuello de la madre, y me dejo yacer en el piso de la curiara, metiendo el rostro en su cabellera, para no ver lo que ocurre y escapar, en ella, al furor que nos circunda. Pero difícil es olvidarlo, con el medio palmo de agua tibia que empieza a chapotear, dentro de la misma canoa, de proa a popa. Dominando apenas el equilibrio de las embarcaciones, vamos de raudal en raudal, picando de proa en los pailones, montando sobre peñas redondas, saltando adelante, sesgándonos de modo vertiginoso para agarrar un rápido de medio lado, siempre en el borde del vuelco, rodeados. de espuma, sobre estas maderas torturadas que chillan por toda la quilla. Y para colmo empieza a llover. Acrece mi horror, ahora, la visión del capuchino, de barbas dibujadas en negro sobre los relámpagos, que ya no dirige la embarcación, sino reza. Con los dientes apretados, resguardando mi cabeza como se resguarda el cráneo del hijo recién nacido en un trance peligroso, Rosario parece de una sorprendente entereza. (176-7)

El cuarto domingo que podría aparecer en el diario sería el del 25 de junio, pero el narrador lo anota como domingo 24, penúltima fecha de las que hará mención en su diario mientras permanece en Santa Mónica de los Venados, siendo la última la del 27 de junio la cual anota sin escribir el correspondiente día de la semana. El sábado 
24 es el día de la llegada a la aldea de Santa Mónica de los Venados, día que queda anotado en el diario como "domingo, 24 de junio" (198). Ahora bien, el error cometido mantiene el esquema establecido y que, consiste en que el domingo sea el día durante el cual se inicia o se toman los pasos más decisivos de la aventura. El domingo, que en realidad es sábado, sustituye al verdadero domingo, domingo 25 , que nunca es mencionado, ya que después de la errónea fecha "domingo, 24 de junio" (198), el diario sólo fijará otra fecha más: la del 27 de junio. Resulta significativo que del sábado hecho domingo se salte a "junio 27 " (205), que sería miércoles para el narrador y no martes como verdaderamente es, y que sea entonces cuando se anuncie que: "Hoy he to. mado la gran decisión de no regresar allá. Trataré de aprender los simples oficios que se practican en Santa Mónica de los Venados... Voy a sustraerme al destino de Sisifo... Los lunes dejarán de ser, para mi, lunes de ceniza, ni habrá por qué recordar que el lunes es lunes..." (206) La solución radica en que el narrador está en otra de esas co. yunturas en que el Final se une con el Principio, y en un momento en el cual las fechas deberán someterse a las tareas del hombre y no éstas a aquéllas. La cita anterior no sólo alude al error cometido dos semanas antes al saltarse el primer lunes vivido fuera de la metrópoli, sino que, simultáneamente, alude a la posibilidad, o tal vez a la necesidad, de nombrar los días de acuerdo a los designios del hombre. El sábado 24, deberá ser domingo 24 porque es el día en que, simbólicamente, se llega a la ciudad de Henoch. Esta ciudad pertenece a los días del Génesis, pero no a los primeros. De por sí, vivir en la ciudad, o en la ciudad embrionatia, implica que los primeros pasos del Génesis ya han sido dados. Poder conjugar la forma verbal "fundar una ciudad" no es tarea de sábados: "Fundar una ciudad. Yo fundo una ciudad. El ha fundado una ciudad. Es posible conjugar semejante verbo. Se puede ser Fundador de una Ciudad..." (198)

El mismo día sábado hecho domingo, se narra la historia del Adelantado, narración en presente que, obviamente, ha sido "reconstruida" - novelada por el narrador: "Bajo el emblema del caduceo, un hombre de veinte años, con el pecho desgarrado por una tos rebelde, mira a la calle a través de las bolas de cristal..." (200) La manera de narrar realza la afinidad que el protagonista quiere ver y que, sin duda, tal y como él la cuenta, existe entre la historia del adelantado y ciertas partes de la suya propia. De joven el adelantado ha vivido en una "ciudad de casas crecidas" (200), donde "no halló sino oficios de sombra" (200). La ciudad es también aquí signo del mal, y su atracción repite el nexo 
domingo-lunes con las mismas consecuencias alienantes: "El joven no envidia a los de su edad que, cada lunes del año, después de haber oido una última misa en la iglesia del púlpito carcomido, salen con sus ropas de domingos, para irse a la ciudad lejana..." (201) En la pequeña biografía del adelantado se narra el camino hacia la posibilidad de fundar y de crear. Esta necesidad de crear y de nombrar está también reflejada en los indios que le ayudan a levantar la ciudad: "Iuego, es la cabra preñada y el becerro destetado, para el cual tienen los indios, como Adán, que inventar un nombre..." (202) La necesidad de nom. brar las cosas puede incluir la de nombrar los días. El error cometido por el narrador es reivindicado a nivel simbólico: el lunes olvidado en realidad no existe, el domingo que es sábado y debiera ser domingo puede, de hecho, serlo. ${ }^{28}$

La omisión de las fechas iniciada tres días después de haberse ins. talado en Santa Mónica de los Venados, cesa el 18 de julio, día en que regresa a la metrópoli y que podemos deducir cae martes. Podemos además establecer que la partida por avión de Santa Mónica de los Venados, partida definitiva, ocurre un domingo; precisamente el séptimo domingo a partir del comienzo de la ficción, con lo cual se da término a la primera semana simbólica vivida por el protagonista. ${ }^{29}$ Este ingresa de nuevo en la vida metropolitana un martes, el mismo día de la se-

28 Con respecto a la "equivocación" de las fechas se puede añadir que el agudo poder de observación del narrador no hubiese pasado por alto ni el primer domingo ni el segundo que comparte con fray Pedro de Henestrosa, ya que éste hubiera dado misa de domingo. Pero lo cierto es que la única misa mencionada en el texto ocurre el martes (miércoles en el diario) 20 de junio, misa de acción de gracias después de la tormenta. El primer domingo que pasa en compañia del fraile transcurre sin la misa que le hubiese revelado que era domingo y no lunes. Es plausible que el fraile no haya podido celebrar misa por encontrarse al descampado, pero es de suponer que al domingo siguiente la hubiese podido celebrar en Santa Mónica de los Venados. Y es precisamente dicho domingo el primero en ser omitido por entero del diario. Puede entonces deducirse que lo que escribe el narrador el día 27 sobre la no necesidad de tener que llamar al lunes lunes, y su aparente decisión de no fechar más su diario a partir de ese momento, refleja, entre otras cosas, el haberse enterado dos días antes (durante el domingo dejado fuera del diario) de su equivocación.

29 La distancia que separa a la aldea de la capital del país se puede cubrir en sólo tres horas de vuelo: "Me admiro al saber que esta ciudad de Henoch, aún sin fraguas, donde acaso oficio yo de Jubal, está a tres horas de vuelo de la capital. . (240). Más tarde, el martes, mientras vuela de regreso a la metrópoli el narrador recuenta su conversación telefónica con Ruth: "De pronto, fueron expresiones de amor, y la noticia de que habia abandonado el teatro para estar siempre junto a mí, y que iba a tomar el primer avión para reunirse conmigo... le grité que permaneciera en nuestra casa y que quien tomaría el avión aquella misma noche sería yo..." (251). Como llega a la metrópoli (Nueva York de seguro) el martes 18 de julio, la conversación debe tomar lugar el lunes y la partida de Santa Mónica de los Venados ęl día antẹior, o sea, el domingo 16 de julio, 
mana en que viviera en ella por última vez antes de marchar a la selva. ${ }^{30}$ La trayectoria de martes a martes realza la sensación de un ciclo que se cierra. Cabe también suponer que la partida de Santa Mónica de los Venados un domingo inicia una progresión hacia el cierre o clausura de la semana (que sería la segunda semana simbólica de la ficción) entendiéndose por semana la unidad simbólica que sirve de núcleo para la organización temporal de la novela.

En este sentido las cuatro últimas fechas anotadas en el diario dicen mucho más de lo que a primera vista parecen decir. Las dos primetas de estas fechas caen viernes: el 20 de octubre y el 8 de diciembre. En la primera de ambas la crisis por la que attaviesa el protagonista se acentúa al extremo de retornar a la despreciada Mouche, pero sólo para enterarse, de nuevo por el azar, de la muerte de fray Pedro de Henes. trosa. La noticia le decide a regresar cuanto antes a Santa Mónica de los Venados. El segundo viernes ( 8 de diciembre) marca su regreso a Puerto Anunciación, donde vuelve a sentirse dueño de sus pasos mientras espera que baje la crecida del tío para poder llegar a la meta de su viaje.

Las dos fechas restantes mencionadas en el diario caen sábado (9 y 30 de diciembre). El primer sábado es el día en que fracasa en su intento de descubrir la puerta que conduce a Santa Mónica de los Venados. El segundo sábado concluye la trama de la novela, después de que el protagonista se entera por boca del mincro griego Yannes de que Rosario se ha casado con Marcos, el hijo del adelantado.

Si nos fijamos en los días de la semana mencionados en el diario a partir de su regreso a la metrópoli veremos que, después de abandonar la aldea un domingo y de regresar a Nueva York un martes las cuatro fechas restantes cuyos días podemos fijar con seguridad corresponden a dos viernes y a dos sábados. La progresión del fin de la Semana (do. mingo) al fin de la próxima (que a nivel simbólico siempre resulta la misma) resulta clara: domingo-martes-viernes-viernés.sábado-sábado. . . La repetición de estos dos últimos días actúa como una especie de redoble, como el anticipo de que el regreso a Santa Mónica de los Venados ocurrirá un domingo. El domingo se va convirtiendo poco a poco en día mágico, en el dia que tendrá que ser recuperado para lograr reingresar en el espacio y tiempo perdidos. A nivel simbólico, podría entonces de-

so Llega a la capital latinoamericana por primera vez el miércoles 7 de junio por avión. El martes 6 de junio, pues, fue el último día completo transcurrido en la metrópoli antes de su partida para Sudamérica. 
cirse, que al protagonista le es negado recuperar dicho domingo, lo cual equivaldría a completar la semana. De esta suposición se desprenderían otras: no puede encontrar la puerta de nuevo porque la puerta sôlo puede ser encontrada el domingo (como lo fuera por vez primera). El que desista de buscarla un sábado sólo reafirma la insuperable distancia temporal creada entre su deseo y el objeto deseado al haber desandado los pasos: "Un día comete el irreparable error de desandar lo andado, creyendo que lo excepcional pueda sérlo dos veces..." (280) Efectivamente, lo excepcional sólo ocurre una vez. La posibilidad de transformar un sábado en domingo que lograra hacer efectiva antes (al convertir el sábado 24 de junio en domingo 24) le es ahora negada. Entre el sábado y el domingo la distancia es ahora infranqueable.

La imposibilidad de completar la semana tiene, sin embargo, un aspecto positivo. El domingo irrecuperable lo es sólo para el protagonista de esta novela. La semana inconclusa representa en su séptimo día el vacío que habrá de ser colmado por el arte. Debemos sospechar que, de haberse cerrado la semana (con el regreso a Santa Mónica de los Venados) la "novela-aventura" nunca hubiese sido escrita. La ausencia del domingo provoca la escritura que, ilusoriamente, tratará de cubrirla $y$, a su vez, deja abierta la posibilidad para que otro visitante, otro ser en busca de los pasos perdidos, pueda entrar, quizás en un futuro no muy lejano, en el domingo mágico, en el domingo que es Final y Principio, apertura hacia el ámbito creador.

Conviene ahora recapitular lo expuesto.

La ficción de Los pasos perdidos ocurre en el año de mil novecientos cincuenta, año que divide al siglo por la mitad de la misma manera en que junio, mes del inicio de la ficción, divide al año. La ficción cubre treinta de los últimos treinta y un domingos del año, dejando sólo de cubrit el último domingo que es, también, el último día del año. Los cuatro primeros domingos sirven de marco para los hechos más cruciales de la aventura en busca de los pasos perdidos; en todos ellos se ingresa en algo, se inicia algo o se concluye algo que tiene que ver con esa "otra dimensión" o apertura, representada por el domingo mismo como ámbito de lo mágico. La aventura asume la semana como unidad básica para organizar su contenido, que nos refiere a la posibilidad de transitar, o de no poder transitar, de un tiempo y de un espacio a otros tiempos y espacios. De los días de la semana es el domingo el que adquiere el valor mágico como puerta de salida o de entrada a la 
"otra orilla". Al principio de la aventura el domingo es "aprovechado", pero al final, cuando parece que la aventura terminará con su recuperación, es cuando se hace inalcanzable. La distancia que media entre el deseo y su objeto se repite entre el sábado y el domingo. Dicha distancia es la que posibilita a su vez, la ficción de ahora y la del futuro. Las semanas y los años se sucederán los unos a los otros y un sábado siempre se disolverá en domingo, pero en la ficción, la Semana y el Año siempre permanecerán abiertos. La ficción consiste en la persistente ilusión de tratar de cerrarlos.

Eduardo G. GonzÁLEZ 
